\title{
Changing concepts in haemochromatosis
}

\author{
L. W. POWELL \\ M.D.(Queensland), M.R.A.C.P.

\begin{abstract}
Reader in Medicine, Department of Medicine, University of Queensland, Royal Brisbane Hospital, Brisbane, Australia 4029
\end{abstract}

As in other countries, idiopathic haemochromatosis has aroused interest and speculation in Australia out of proportion to its frequency and clinical importance. This is probably due to its distinctive clinical features and to the fact that it may hold the key to the mechanism of normal iron absorption. Maddox \& Durie (1934) noted that, whereas only 175 cases had been reported in the world literature by 1932, the disease was probably commoner than these statistics indicated, and that it was unlikely that the figure included Australian cases. Six cases had been reported in Australia by 1932 (Grieve, 1932; Stokes, 1926; Russell, 1925; McWhae, 1922) and Maddox and Durie reported a further four patients, three of whom appeared simultaneously in the same medical ward at the Royal Prince Alfred Hospital, Sydney. A feature of the disease emphasized by these writers was the pigmentation, as the patient 'may deny that it is anything more than his usual summer tan, a local difficulty which does not occur in England'. In addition to pigmentation of the skin, they noted a diffuse slaty-blueish colour of the hard palate and a similar discoloration of the retina. In three of their patients the latter phenomenon was associated with an ochre coloured background in the periphery of the fundus (Maddox, 1933). In 1941, Rupert Willis described the post mortem findings in seven fatal cases seen at the Alfred Hospital, Melbourne. Three of the patients had died from a hepatoma, apparently multicentric in origin. Further cases of haemochromatosis were reported by Walsh \& King (1950), McGuinness (1953), Saint \& Hunt (1955), Wigley \& King (1956) and Paterson (1958). Kaldor (1953) in the third of a series of twelve papers on Intermediary Iron Metabolism from the New South Wales Red Cross Blood Transfusion Service, Sydney, lucidly demonstrated the diagnostic value of the percentage saturation of the total iron-binding capacity in haemochromatosis and other conditions affecting iron metabolism. A further major Australian contribution to the literature on haemochromatosis came from Ian Wood's group at the Walter and Eliza Hall
Institute, Melbourne (Althausen et al., 1951). They performed a comprehensive clinical, nutritional and biochemical study of twenty-three patients with haemochromatosis and showed that the diets of these patients did not differ significantly from those of normal subjects in protein, caloric or mineral content. They also appear to have been the first workers to investigate exocrine pancreatic function in haemochromatosis, finding hypersecretion of an enzymepoor juice.

Saint (1963) discussed haemochromatosis at length in his Edward Stirling Lectures in 1962, drawing on his own extensive experience of the disease in Melbourne and Perth. He emphasized the possible regional difference in prevalence of the disease in the western world, due largely to variations in dietary intake of iron, there being a low incidence in Britain and a relatively high incidence in Australia, a great meat-eating country. Based on a comparison of admissions to the Glasgow Western Infirmary and the Royal Perth Hospital, Saint deduced that the incidence of overt haemochromatosis in Australia was at least three times that in northern Britain, and his 'uninspired hunch' was that the Australian prevalence of the disease was of the order of 30 per 100,000 . In addition, he noted a relatively high prevalence of the disease in Australian women and a high incidence of alcoholism ( $50 \%$ ) in the Australian series.

Some of the most striking family studies of idiopathic haemochromatosis have been reported from Australia. Morgan (1961) performed a detailed study of seventy immediate relatives of twenty-three patients in Perth, and found abnormalities in serum iron levels in $27 \%$ of the relatives although only two relatives had detectable abnormalities of liver function. Morgan concluded that the results were compatible with inheritance of an abnormality of iron metabolism by an autosomal dominant gene and that the alteration in iron metabolism preceded the liver damage even if the two were not causally related. The significance of alcohol ingestion and dietary iron in altering the pattern of the disease in 
families was emphasized in the Brisbane studies of Harris (1962), Lloyd, Powell \& Thomas (1964) and Powell (1965). The family reported by Lloyd et al. (1964) was unusual in that the disease was fully expressed in two generations of women, two of whom were menstruating. The excess iron stores have since been removed by venesection therapy (total amounts of 19 and $11.5 \mathrm{~g}$ iron respectively, followed by $250 \mathrm{mg}$ every 3 months) and both women still have regular menses. In the remarkable family reported by Perkins et al. (1965) the propositus exhibited the full syndrome of haemochromatosis at the age of 13 years and three younger siblings were also affected. The authors reviewed the literature on juvenile haemochromatosis and concluded that haemochromatosis in children represents a severe form of the adult disease rather than a separate entity. Deller et al. (1969) described a South Australian family in whom they postulated that six members suffered from the genetic form of the disease, while in another member, a brother of the propositus, iron overload was secondary to alcoholic cirrhosis.

One of the largest genetic studies of idiopathic haemochromatosis ever reported was carried out at the Red Cross Blood Transfusion Centre, Sydney, by Dr R. J. Walsh, now Professor of Human Genetics, University of New South Wales. Walsh and his collaborators (Walsh, Perkins \& Blackburn, 1964) systematically examined and investigated more than 160 relatives of patients with idiopathic haemochromatosis using standard clinical methods and an ironchelation test (Walsh et al., 1963). They found that approximately $25 \%$ of siblings showed evidence of iron overload, whereas this was rare in parents or offspring, and they concluded that these findings were most likely due to inheritance of an autosomal recessive gene, with a gene frequency in Australia of about 1 in 150 . Walsh (personal communication) believes that in a minority of patients there is a second mode of inheritance, by an autosomal dominant gene. This would explain those rare families reported where the overt disease is present in two or even three generations.

The treatment and prognosis of haemochromatosis have also received attention in this country. Blackburn, McGuinness \& Kaldor (1953) reported a case illustrating the value of repeated venesection and the importance of serial studies in the control of therapy. Sewell (1956) described 'dramatic improvement' in a patient after 180 venesections. His patient lost all symptoms, the liver returned to almost normal size and glucose tolerance also returned to normal. However, the patient reported by Hurst, Kakulas \& Walters (1961) emphasized that such treatment does not necessarily prevent the development of a hepatoma. Hennessy, Biggs \& Garvan (1967) presented the follow-up data of a series of forty-one patients with haemochromatosis seen at St Vincent's Hospital Sydney. At the time of study twenty-one of the patients were dead and necropsy examination was performed in twelve. Seven of the twelve died from a hepatoma, including two sisters with the disease. Of these seven patients three had undergone repeated venesection therapy for periods ranging from 3 months to 6 years.

Theories of pathogenesis of idiopathic haemochromatosis implicating abnormal luminal factors have been proposed by Davis and Biggs of Sydney (Biggs \& Davis, 1963; Davis \& Biggs, 1964) and Deller and his colleagues in Adelaide (Davis, Luke $\&$ Deller, 1966). Both theories have resulted in considerable debate at Australian medical conferences and in the world literature, and have stimulated much experimental work into the role of pancreatic and gastric secretions in iron absorption. These theories are discussed in more detail later in this paper.

The endocrine and metabolic aspects of the disease have been little studied in Australia. However, Stocks \& Martin (1968) performed a comprehensive study of pituitary and gonadal function in fifteen patients with idiopathic haemochromatosis. Their investigations included testicular biopsy and the estimation of the levels of urinary oestrogen, plasma testosterone and several pituitary hormones. They concluded that hypogonadism in haemochromatosis was due to pituitary involvement, possibly secondary to iron deposition in this organ.

The general concept of haemochromatosis has broadened since Sheldon's original suggestion of a specific inborn metabolic error leading to the distinctive clinico-pathological picture of the disease (Sheldon, 1935). Thus, it is now generally agreed that the extent of iron storage in any particular individual is determined not only by the severity of the gastrointestinal absorptive defect, but also by other extraneous factors which can materially alter the rate of iron absorption or iron loss. Such factors include the amount and form of iron in the diet, the amount and types of alcoholic beverages ingested, the presence of liver damage from alcohol or other causes, the age of the subject and the rate of iron loss (Charlton et al., 1964; Callender \& Malpas, 1963; Conrad, Berman \& Crosby, 1962). It is also evident that prolonged exposure to a high dietary intake of iron and alcohol can result in the clinical and pathological picture of haemochromatosis without the presence of a fundamental metabolic defect in iron absorption (Isaacson et al., 1961; MacDonald, 1961, 1963). Furthermore, the complete syndrome can be produced by secondary accumulation of tissue iron in patients with preexisting cirrhosis (Sabesin \& Thomas, 1964) especially after portacaval anastomosis (Tuttle, Figueroa \& Grossman, 1959). 
Recent work has thus been concerned with the definition of haemochromatosis and its causes, especially in relation to dietary habits and alcoholism, and with the nature of the fundamental metabolic defect in idiopathic haemochromatosis. In addition, with more detailed follow-up studies, including serial liver biopsies, a clearer picture of the natural history of idiopathic haemochromatosis, with and without venesection therapy, has emerged.

\section{Definition of haemochromatosis and its relation to alcoholism}

There has been considerable debate and confusion as to the criteria acceptable for the diagnosis of haemochromatosis ever since it was realized that patients with hepatic cirrhosis may develop skin pigmentation, diabetes mellitus, a high serum iron level with saturation of the iron-binding protein, and various degrees of parenchymal iron deposition in the liver and other organs (Bell, 1955; Conrad et al., 1962; MacDonald \& Pechet, 1964; Pechet et al. 1965). Certainly, the diagnosis of haemochromatosis should not be based merely on suggestive clinical features, nor solely on the presence of parenchymal iron deposition in the liver in association with cirrhosis. Some attempt should be made to quantitate the degree of iron excess (Table 1). This can be done by measurement of the amount of iron removed by repeated venesections (Haskins et al., 1952), by quantitative tests using iron-chelating agents (Walsh et al., 1963; Walsh et al., 1964; Fielding, 1965; Powell \& Thomas, 1967) or by chemical analysis of tissue obtained by biopsy or at necropsy.

Concentrations of iron in excess of $1.0 \%$ dry weight are found in the liver in haemochromatosis (Sheldon, 1935), and this is considerably greater than the tissue concentration of iron which is present in patients with cirrhosis plus visible haemosiderin

TABle 1. Definitions

HAEMOCHROMATOSIS

Tissue damage with increased total body iron stores

Clinical Criteria: $\quad$ Tissue damage (biopsy) $+$

increased body iron (assessed by response to repeated venesections or the injection of a chelating agent)

Pathological Criteria: Tissue damage $+$

grossly increased iron concentration in parenchymal and other cells of the liver and other organs, e.g. pancreas, heart (preferably assessed by chemical analyses)

IDIOPATHIC HAEMOCHROMATOSIS: Haemochromatosis developing in the absence of known causes of secondary iron overload (see Table 2) preferably in association with a family history of iron storage disease

LATENT OR PRE-CIRRHOTIC IDIOPATHIC HAEMOCHROMATOSIS Increased body iron stores associated with increased iron absorption and a family history of iron storage disease deposits (MacDonald \& Pechet, 1965; Pechet et al., 1965; Powell, 1966). Clinically, the distinction between haemochromatosis and cirrhosis with haemosiderosis can usually be made on the basis of the response to chelating agents and repeated venesections. In contrast to patients with haemochromatosis, those with cirrhosis and secondary haemosiderosis have usually only a slight increase in chelatable body iron (Walsh et al., 1965; Powell \& Thomas, 1967) and normal or slightly increased amounts (1.0-2.5 g) of iron mobilizable by venesections (Conrad et al., 1962; Williams et al., 1967). Further information still may be obtained from family studies. Abnormalities of iron metabolism occur in over $25 \%$ of first-degree relatives of patients with idiopathic haemochromatosis whereas such abnormalities are very infrequent in relatives of patients with cirrhosis and haemosiderosis, even in those relatives who consume alcohol to excess (Powell, 1965).

Thus, in summary, the diagnosis of haemochromatosis should be made at present on the basis of histological proof of tissue damage, preferably wellestablished or at least early cirrhosis, associated with convincing evidence of grossly increased body iron stores. Idiopathic haemochromatosis is diagnosed by exclusion of the known causes of secondary haemochromatosis, such as chronic refractory or haemolytic anaemia, portacaval anastomosis and so on, and by family studies. The causes of secondary haemochromatosis are usually easily recognized (Table 2). However, diagnostic problems may arise in alcoholic patients, especially social derelicts, in whom family studies reveal no abnormality of iron metabolism and in whom previous histological material is unavailable. In such patients it may be impossible to distinguish with certainty between idiopathic haemochromatosis aggravated by alcoholism and haemochromatosis of the Bantu type (Tyrer, Powell \& Burnett, 1966). It is noteworthy, however, that there are differences between the clinical and pathological features of idiopathic haemochromatosis and those exhibited by the majority of patients with Bantu haemochromatosis (Charlton \& Bothwell, 1966). This applies particularly to the distribution of iron deposits in the liver and

TABLE 2. Classification of haemochromatosis

1. Primary or Idiopathic Haemochromatosis

(a) latent or pre-cirrhotic stage

(b) cirrhotic stage

2. Secondary Haemochromatosis

(a) chronic refractory anaemias

(b) hepatic cirrhosis with secondary iron accumulation e.g. after portacaval anastomosis

(c) chronic alcohol ingestion associated with excess dietary iron ('Bantu-type haemochromatosis')

(d) congenital transferrin deficiency 
spleen (Bothwell et al., 1965). On the other hand, in a study of alcoholic and non-alcoholic patients with haemochromatosis in Brisbane, we were unable to demonstrate any significant difference between the two groups with respect to the clinical and pathological features or the degree of iron overload, except for the presence of active hepatocellular disease in some alcoholic patients (Powell, unpublished). This suggests that the majority of alcoholic patients with haemochromatosis have the genetic form of the disorder which has been accelerated or modified by alcoholism and, in some cases, by superimposed alcoholic liver disease. This is in accord with reported epidemiological studies of hepatic iron storage which suggest that, except in the South Africa Bantu, the consumption of iron-containing alcoholic drinks does not correlate closely with the incidence of iron-storage disease (MacDonald \& Pechet, 1965; Block et al., 1965; Charlton \& Bothwell, 1966). When gross iron deposition does follow pre-existing cirrhosis, a cause is often apparent, such as portacaval anastomosis, haemolysis or prolonged iron administration.

\section{Early or pre-cirrhotic haemochromatosis}

The definition of idiopathic haemochromatosis given above evades the important practical issue of the recognition of the early, pre-cirrhotic, or latent stage of the disease. The recognition of affected relatives is important for epidemiological, diagnostic and therapeutic reasons. However, while the demonstration of elevated serum iron concentrations, increased saturation of the total iron-binding capacity, or increased storage iron in relatives is strong evidence for the genetic theory of aetiology of idiopathic haemochromatosis, such abnormalities may not reliably identify those relatives who will later develop the full clinical syndrome. Indeed, we have observed relatives who exhibited such abnormalities of iron metabolism but in whom there has been no apparent progression of the disorder for up to 8 years. This may be due to variable penetrance and expression of the genetic defect or perhaps to too short a period of follow-up. Until the fundamental defect leading to increased iron absorption in this disease is known, or until a reliable genetic marker is available, the pre-cirrhotic stage of idiopathic haemochromatosis is probably diagnosed most reliably in relatives by the demonstration of increased iron absorption, especially in association with increased iron stores and in the absence of other known causes such as chronic anaemia (Williams et al., 1965; Balcerzak et al., 1966).

\section{Possible metabolic defect in idiopathic haemochromatosis}

The factors believed to be important in the regulation of normal iron absorption are summarized in Fig. 1.
The metabolic fault leading to inappropriate iron absorption in subjects with idiopathic haemochromatosis remains an enigma. For many years after Sheldon's suggestion of a specific inborn metabolic error it was thought that the primary defect was at the site of the intestinal mucosal cell. Later, it was felt more likely that the increased iron absorption was a secondary phenomenon and various suggestions were made as to the primary defect. These included an increased tissue avidity for iron as a result of excessive synthesis of a tissue iron-binding protein (Goldberg \& Smith, 1960) a deficiency in tissue xanthine oxidase, which may be responsible for mobilization of hepatic storage iron (vide infra) and an alteration in reticulo-endothelial function with an altered gradient between reticulo-endothelial cells and the plasma (Bothwell et al., 1959; MacDonald, Endo \& Pechet, 1968).

\section{Luminal factors}

Recent interest, however, has centred more on the possibility of abnormal luminal factors. Pancreatic insufficiency, for example, could theoretically contribute to the syndrome of haemochromatosis by increasing iron absorption (Biggs \& Davis, 1963) and by producing diabetes mellitus. However, while there is good evidence that some patients with chronic pancreatic disease absorb iron excessively, it has not been established that this is a direct effect of pancreatic insufficiency, and the role of pancreatic exocrine secretions in the physiological control of iron absorption is uncertain (Kavin et al., 1967). Davis (personal communication) has found hypersecretion of an enzyme-poor juice in patients with untreated haemochromatosis but this abnormality tended to return to normal after venesection therapy.

Similarly, there has been considerable interest in possible abnormalities in gastric juice in patients with idiopathic haemochromatosis. While it is known that normal gastric juice influences iron absorption, probably by facilitating chelation of inorganic iron (Koepke \& Stewart, 1964; Schade, Cohen \& Conrad, 1968; Jacobs \& Miles, 1969) the evidence relating to abnormalities in gastric juice in patients with idiopathic haemochromatosis is conflicting. Murray \& Stein (1968) showed that neutralized gastric juice from patients with haemochromatosis increased intestinal uptake of iron by everted rat-gut segments and in the intact rat. However, Smith, Studley \& Williams (1969) could not confirm these findings in vitro. In contrast, Davis et al. (1966) produced evidence for a specific gastric inhibitor of iron absorption and for a deficiency of this substance in subjects with idiopathic haemochromatosis. Wynter \& Williams (1968) were unable to confirm this observation. Likewise, we have found no difference in gastric iron binding between normal subjects and 


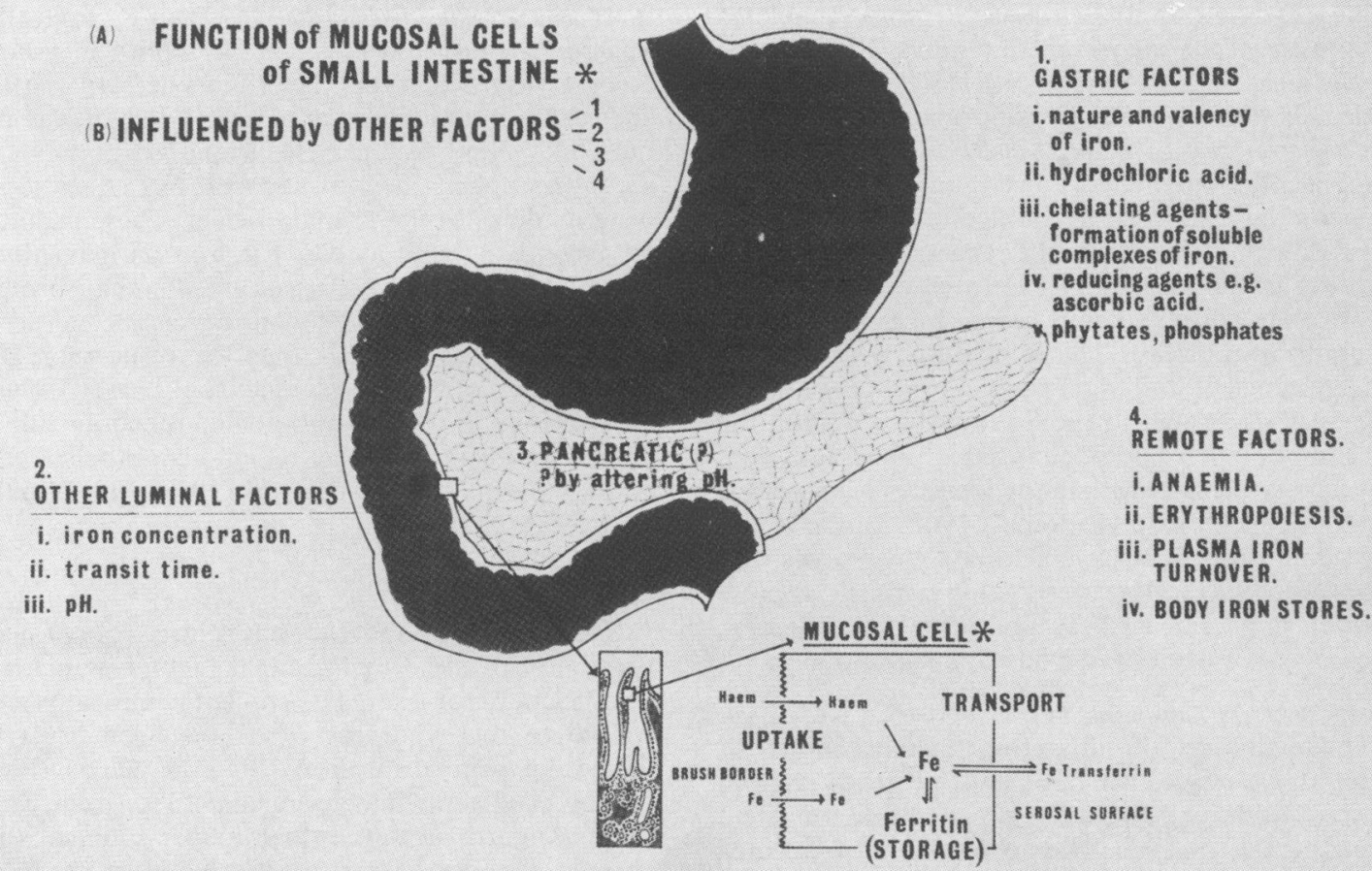

FIG. 1. Factors believed to be involved in normal iron absorption. A degree of control over intestinal uptake and transport of iron resides in the mucosal cells of the upper small intestine and this is influenced by many other factors, both luminal and corporeal. It remains uncertain whether the site of the metabolic defect in subjects with idiopathic haemochromatosis is at the luminal, mucosal or corporeal level.

patients with idiopathic haemochromatosis and no correlation between iron-binding ability and in vivo mucosal uptake of iron or iron absorption (Powell \& Wilson, 1969).

\section{Mucosal control of iron absorption}

Some recent work has redirected attention to the mechanisms of control of iron absorption by the intestinal mucosal cell and suggests that the primary abnormality in idiopathic haemochromatosis may lie in this area. It is generally believed that iron absorption takes place by a two-step mechanism (Fig. 1) with a rapid initial uptake by the mucosa and transfer across the cell by a nonprotein iron compound, followed by a second phase in which proteinbound iron, probably ferritin, accumulates in the cell, with a further slow transfer of iron to the blood (Manis \& Schachter, 1962; Conrad \& Crosby, 1963; Brown \& Rother, 1963; Charlton et al., 1965; Boender \& Verloop, 1969). Under normal circumstances, only a proportion of iron taken up by the mucosal cell is retained in the body; the rest is stored in the mucosal cell and lost with the normal exfolia- tion of the intestinal epithelium. Boender and his colleagues (Boender, et al., 1967; Boender \& Verloop, 1969) attempted to determine how much of the iron initially absorbed by the intestinal cell was later excreted in the faeces, by administering a test dose of radio-active iron $\left({ }^{59} \mathrm{Fe}\right)$ with radioactive barium sulphate $\left.{ }^{{ }^{131}} \mathrm{Ba}\right)$ as a non-absorbable marker. In normal subjects and patients with secondary haemosiderosis, a large proportion (approximately $25-70 \%$ ) of the iron initially absorbed was excreted, whereas in patients with iron deficiency nearly all the initially absorbed iron was retained. Six patients with 'idiopathic haemosiderosis' (probably early idiopathic haemochromatosis) were studied and are of particular relevance to the present discussion. In two patients, body retention of iron was virtually identical to initial mucosal uptake, although the latter was at the upper limit of the normal range. Two further subjects, who had previously been treated by venesection therapy, showed the pattern of mucosal uptake and body retention of iron seen in irondeficiency anaemia. The fifth subject was a 22-yearold son of one of the above patients and showed 
increased saturation of the plasma iron-binding capacity without evidence of increased iron stores. In this patient both mucosal cell uptake and body iron retention were elevated, although $17 \%$ of the absorbed dose of ${ }^{50} \mathrm{Fe}$ was excreted. In the sixth subject both uptake and retention were elevated but $34 \%$ of the absorbed dose was later excreted. This high iron excretion may have been a consequence of a partial gastrectomy performed 8 years earlier. The authors concluded from this study that patients with early idiopathic haemochromatosis showed the same pattern of mucosal uptake and absorption of iron as patients with iron depletion, in spite of the iron overload. But the subjects formed a small and heterogeneous group.

We have performed a similar study using ${ }^{51} \mathrm{Cr}$ chromic chloride as the non-absorbable marker, and administered the solution containing the marker and radioactive iron during a standard meal in order to obtain information about the pattern of uptake and absorption of iron from a normal diet (Powell, Wilson \& Campbell, unpublished). Mucosal uptake of iron was calculated from the change in the relative concentrations of ${ }^{51} \mathrm{Cr}$ and ${ }^{59} \mathrm{Fe}$ between the standard solution ingested and the first sample of faeces which contained the marker. Body iron absorption was measured by whole-body counting or by a double-isotope technique using ${ }^{59} \mathrm{Fe}$ orally and ${ }^{55} \mathrm{Fe}$ intravenously. The results obtained in normal subjects and patients with iron-deficiency (Table 3) are very similar to those of Boender \& Verloop (1969) except that our figures for mucosal uptake and body retention of iron are lower, owing to the fact that the iron was administered with a meal. The results in patients with early and untreated haemochromatosis are of interest, because, although rather variable within these groups, body iron retention was increased in three patients while mucosal uptake was in the upper normal range. Similar findings were obtained by Boender \& Verloop in two of their patients. This would seem to point to a mucosal defect rather than a luminal abnormality as the mechanism leading to excessive absorption of iron in this disease.

In view of the above findings it is of interest that, compared with normal subjects, patients with idiopathic haemochromatosis have little ferritin visible on electron microscopy of the epithelial cells of the intestinal villi (Crosby, 1963) and fewer iron-loaded macrophages appear to enter the intestinal lumen (Cattan et al., 1967; Astaldi, Meardi \& Lisino, 1966).

\section{Mucosal xanthine oxidase activity and iron absorption}

If the metabolic fault in subjects with idiopathic haemochromatosis is at the mucosal level what is the possible abnormality? An inherited defect in a mucosal enzyme controlling iron absorption is an attractive hypothesis but evidence for such a defect is lacking. Indeed, knowledge of the role of mucosal cell enzymes in iron absorption is still meagre. However, recently published work from two independent sources suggests that mucosal enzymatic activity is involved in iron absorption. Weintraub, Dawson \& Rafal (1968) described evidence for a direct effect of xanthine oxidase stimulating the release of iron from haem in mucosal homogenates. Secondly, Manis (1969) showed that sucrose homogenates of rat intestinal mucosa oxidized ferrous to ferric iron suggesting enzymatic action and that the duodenum contained more activity per mg of protein than did the distal ileum. As long ago as 1957 it was suggested that xanthine oxidase was the enzyme responsible for the mobilization of storage iron from the liver (Green \& Mazur, 1957; Mazur et al., 1958) and since there is a high concentration of this enzyme in the intestinal

TABLE 3. Mucosal cell uptake and body iron absorption in patients with idiopathic haemochromatosis and controls

\begin{tabular}{|c|c|c|c|}
\hline Group* & & $\begin{array}{l}\text { In vivo mucosal } \\
\text { uptake }(\dagger) \\
(\% \text { of dose } \\
\text { administered) }\end{array}$ & $\begin{array}{c}\text { Body iron absorption } \\
\text { ( } \% \text { of dose } \\
\text { administered) }\end{array}$ \\
\hline Normal controls & (17) & $10 \cdot 4 \pm$ S.D. $4 \cdot 9$ & $2 \cdot 4 \pm$ S.D. $2 \cdot 3$ \\
\hline Iron deficiency & (5) & $30 \cdot 7 \pm$ S.D. $16 \cdot 5$ & $26 \cdot 5 \pm$ S.D. $18 \cdot 4$ \\
\hline $\begin{array}{l}\text { Haemochromatosis } \\
\text { after iron stores } \\
\text { removed by vene- } \\
\text { section therapy }\end{array}$ & (8) & $27 \cdot 2 \pm$ S.D. $11 \cdot 9$ & $26 \cdot 5 \pm$ S.D. $14 \cdot 6$ \\
\hline $\begin{array}{l}\text { Haemochromatosis- } \\
\text { no venesection } \\
\text { therapy }\end{array}$ & (3) & $\begin{array}{l}10 \cdot 4 \\
14 \cdot 3 \\
11 \cdot 8\end{array}$ & $\begin{array}{r}1 \cdot 8 \\
11 \cdot 8 \\
10.7\end{array}$ \\
\hline $\begin{array}{l}\text { Early 'pre-cirrhotic' } \\
\text { haemochromatosis } \ddagger\end{array}$ & (2) & $\begin{array}{c}17 \cdot 9 \\
0\end{array}$ & $\begin{array}{l}9 \cdot 5 \\
0\end{array}$ \\
\hline
\end{tabular}

* The number of patients studied is shown in parentheses.

$\dagger$ For method used see text.

¥ These were relatives of patients with idiopathic haemochromatosis and had grossly increased iron stores without cirrhosis. 
mucosa of rats (Westerfield \& Richert, 1952; Mazur \& Carleton, 1965; Awai \& Brown, 1969), a similar role for xanthine oxidase in releasing iron from ferritin in the intestinal mucosal cell was suspected. However, the evidence bearing on the possible role of this enzyme in iron absorption and in idiopathic haemochromatosis is equivocal (Cheney \& Finch, 1960; Kinney, Kaufman \& Klavins, 1961 ; Seegmiller et al., 1964; Strohmeyer et al., 1964; Ayvazian, 1964; Powell \& Emmerson, 1966; Davis \& Deller, 1966; Udall \& Bushby, 1966; Gevirtz, 1967; Mazur \& Sackler, 1967; Awai \& Brown, 1969). In the most recent and comprehensive study, Awai \& Brown (1969) found decreased xanthine oxidase activity in the intestinal mucosa but increased activity in liver in iron-deficient rats. Marked inhibition of xanthine oxidase activity with allopurinol was associated with increased initial absorption of ${ }^{59} \mathrm{FeSO}_{4}$ but diminished total absorption over 9-11 days, suggesting that the second or later phase of iron absorption is influenced by xanthine oxidase inhibition. Haemoglobin-iron absorption was diminished by allopurinol under conditions of anaemia. This observation may be explained by the observation of Weintraub et al. (1968) mentioned above, of a direct effect of xanthine oxidase stimulating the release of iron from haem in intestinal mucosa. Clearly, further detailed studies are required to determine the exact roles of the ferritin-xanthine oxidase and the haem-xanthine oxidase systems in the mucosal control of iron absorption and their relevance, if any, to idiopathic haemochromatosis.

\section{Natural history of idiopathic haemochromatosis and influence of venesection therapy and alcoholism}

Few detailed studies have been published of the prognosis of patients with idiopathic haemochromatosis making due allowance for such factors as diabetes mellitus, alcoholism, extent of venesection therapy, length of follow-up and severity of the disease at the time of diagnosis. As emphasized by Finch \& Finch (1955), there have been three distinct periods in the treatment and therefore prognosis in this disease. The first was the pre-insulin era in which most patients died in diabetic coma weeks or months after the onset of symptoms. The second was the insulin era in which the principal causes of death were hepatic failure, portal hypertension, cardiac failure and infection, with an average survival of $4 \cdot 4$ years after signs of clinical disease became manifest. From the most recent period, or venesection era, have come several reports of subjective and objective improvement in those patients presenting with cardiac manifestations, the prognosis in whom was previously very poor (McAllen, Coghill \& Lubran, 1957; Perkins et al., 1965; Charlton \& Bothwell, 1966). However, evidence that venesection therapy significantly alters the progress of the hepatic disease has been less convincing and the value of such therapy seriously challenged (MacDonald, 1966), especially as it is known that occasional patients can survive for up to 20 years without therapy (Finch \& Finch, 1955). The recent study by Williams et al. (1969) probably provides the best evidence to date that venesection therapy in idiopathic haemochromatosis significantly improves prognosis. These authors studied the clinical, biochemical and histological changes in a series of forty patients and compared the findings with those in a group of eighteen untreated patients who had died before venesection was widely accepted. The mean survival for the treated and untreated groups averaged 8.2 and 4.9 years respectively and the respective 5-year mortality was $11 \%$ and $67 \%$. Beneficial changes also included a decrease in skin pigmentation and hepatosplenomegaly, improvement in liver function tests, improved carbohydrate tolerance in about one-third of patients with diabetes, and histological improvement in five of twenty-eight patients $(18 \%)$ in whom follow-up histological material was available. In two patients who had a definite cirrhosis initially, 'an almost normal lobular pattern' was found in percutaneous biopsy specimens after four and fifteen years respectively. The authors emphasized that the two groups were not treated concurrently and there were also differences with respect to age of presentation and incidence of diabetes mellitus. However, the untreated group did not contain a higher proportion of patients with advanced disease and the majority of deaths in this group were directly related to haemochromatosis, whereas in the treated group these represented less than half. Four patients in the treated series developed a hepatoma compared with three in the untreated group. We have obtained similar results in an analysis of fifty-one patients treated at the Royal Brisbane Hospital over the past 15 years except that alcoholic patients fared less well and no significant effect of venesections on prognosis was observed in this group (Table 4). The cumulative survival rate for the group as a whole was significantly better than that reported by Powell \& Klatskin (1968) for a group of ninety-three patients with alcoholic cirrhosis who had stopped drinking (Fig. 2).

The apparent reversal of cirrhosis after prolonged venesection therapy in a minority of patients with idiopathic haemochromatosis is of special interest because, if confirmed by operative biopsies and necropsy studies, this will provide very strong evidence for the noxious effect of severe siderosis in this disease. Weintraub, Conrad \& Crosby (1966) reported two patients in whom venesection therapy was associated with return to normal lobular architecture after 8 years although minimal fibrosis remained. A similar observation was made by Pirart 
TABLE 4. Effect of venesection therapy on prognosis of haemochromatosis

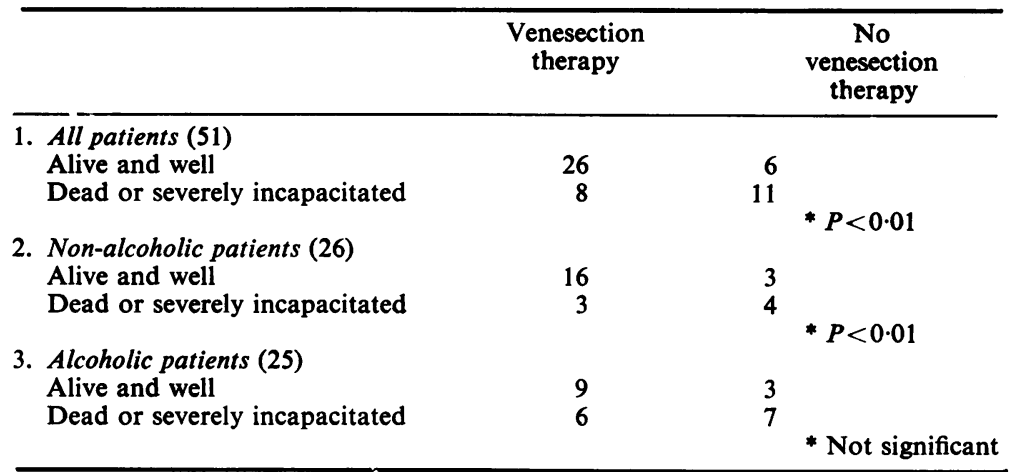

* Exact probability test (Fisher).

(1964) in a 47-year-old man after 5 years. Knauer, Gamble \& Monroe (1965) reported complete reversal of cirrhosis to normal architecture as judged in a wedge-biopsy specimen after a 6-year period. We have treated two patients in whom there has been apparent reversal of the cirrhosis after 15 years (Powell \& Kerr, 1970).

In addition to providing evidence for the toxic effect of haemosiderosis such cases raise the question of the nature of the cirrhosis in haemochromatosis. In non-alcoholic patients the cirrhosis is usually characteristic with dense fibrous septa forming a network which surrounds groups of lobules as is often seen in chronic biliary disease (Knoblauch \& Hedinger, 1963; Scheuer, 1968). The septa gradually

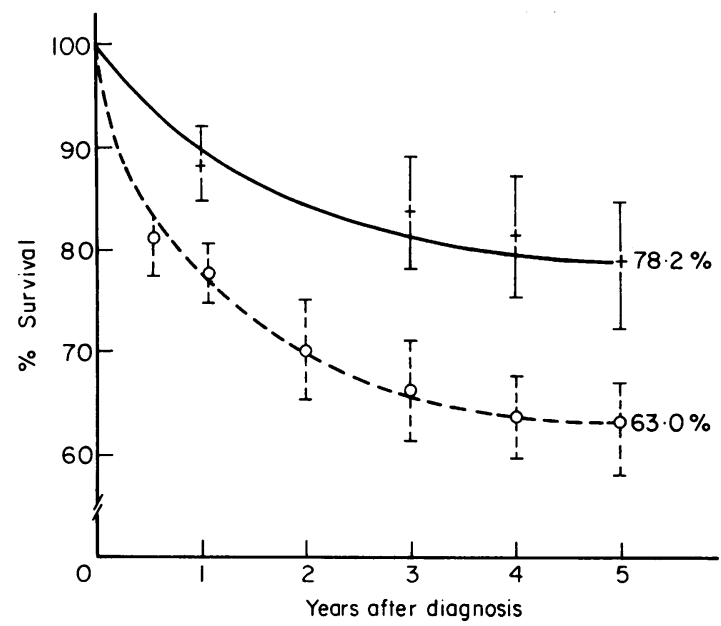

Fig. 2. Cumulative survival after diagnosis in fifty-one patients with haemochromatosis (solid line) compared with that reported by Powell \& Klatskin (1968) for ninety-three patients with alcoholic cirrhosis who had stopped drinking (interrupted line). The vertical lines at each time interval represent \pm 1 standard error and the differences between the two curves are statistically significant at the fifth year $(P<0.001)$. Both curves were constructed by the same life-table method. encroach on the parenchyma but true nodularity and disturbed lobular architecture are late features of the disease. Regression of the early lesions might be expected after removal of the excess iron but, in addition, the reports cited above suggest that improvements can be anticipated even after frank nodularity has developed. In view of the resemblance to chronic biliary disease it is of interest that reversal of biliary cirrhosis has been described after relief of biliary obstruction (Bunton \& Cameron, 1963).

Clearly, the response of the hepatic lesion to removal of iron will depend on several factors, including the stage at which the diagnosis is made, the rate of removal of iron and the presence of superimposed alcoholic liver disease. However, the evidence now available would seem to justify intensive venesection therapy in patients with idiopathic haemochromatosis and also in relatives with moderate or gross heptatic siderosis but without tissue damage.

\section{References}

Althausen, T.L., Doig, R.K., Weiden, S., Motteram, R.. TURNER, C.N. \& MOORE, A. (1951) Haemochromatosis: an investigation of 23 cases with special reference to etiology, nutrition, iron metabolism and studies of hepatic and pancreatic function. Archives of Internal Medicine, 88, 553.

Astaldi, G., Meardi, G. \& Lisino, T. (1966) The iron content of jejunal mucosa obtained by Crosby's biopsy in haemochromatosis and haemosiderosis. Blood, 28, 70.

AWAI, M. \& Brown, E.B. (1969) Examination of the role of xanthine oxidase in iron absorption in the rat. Journal of Laboratory and Clinical Medicine, 73, 366.

Ayvazian, J. (1964) Xanthinuria and haemochromatosis. New England Journal of Medicine, 270, 18.

BeLL, E.T. (1955) Relation of portal cirrhosis to haemochromatosis and to diabetes mellitus. Diabetes, 4, 435.

Balcerzak, S.P., Westerman, M.P., Lee, R.E. \& Doyle, A.P. (1966) Idiopathic hemochromatosis. American Journal of Medicine, 40, 857.

Biggs, J.C. \& Davis, A.E. (1963) Relationship of diminished pancreatic secretion to haemochromatosis. Lancet, ii, 814.

BLACKBURN, C.R.B., McGuINNESS, A.E. \& KALDOR, I..(1953) Removal of excess body iron in haemochromatosis by repeated venesection. Australasian Annals of Medicine, 2, 202. 
Bothwell, T.H., Cohen, I., Abrahams, O.L. \& Perold, S.M. (1959) A familial study in idiopathic hemochromatosis. American Journal of Medicine, 27, 730.

BothWell, T.H., Abrahams, C., Bradlow, B.A.\& Charlton, R.W. (1965) Idiopathic and Bantu hemochromatosis. Comparative histological study. Archives of Pathology, 79, 163.

Block, M., Moore, G.E., Wasi, P. \& Haiby, G. (1965) Histogenesis of the hepatic lesion in primary hemochromatosis with consideration of the pseudo iron deficient state produced by phlebotomies. American Journal of Pathology, 47, 89.

BoENDER, C.A. \& Verloop, M.C. (1969) Iron absorption, iron loss and iron retention in man: studies after oral administration of a tracer dose of ${ }^{59} \mathrm{FeSO}_{4}$ and ${ }^{131} \mathrm{BaSO}_{4}$. British Journal of Haematology, 17, 45.

Boender, C.A., Mulder, E., Ploem, J.E., de Wael, J. \& VERLOOP, M.C. (1967) Iron absorption and retention in man. Nature (London), 213, 1237.

Brown, E.B. \& Rother, M.L. (1963) Studies of the mechanism of iron absorption. I. Iron uptake by the normal rat. Journal of Laboratory and Clinical Medicine, 62, 357.

Bunton, G.L. \& CAMERON, R. (1963) Regeneration of liver after biliary cirrhosis. Annals of the New York Academy of Sciences, 111, 412.

Callender, S.T. \& Malpas, J.S. (1963) Absorption of iron in cirrhosis of the liver. British Medical Journal, 2, 1516.

Cattan, D., Marche, C., Jori, G.P. \& Debray, C. (1967) Le stock martial des villosités duodéno-jéjunales. L'absorption martiale vue par l'histologie. Nouvelle Revue Française d'Hématologie, 7, 259.

Charlton, R.W. \& Bothwell, T.H. (1966) Hemochromatosis: dietary and genetic aspects. In: Progress in Hematology (Ed. by E. B. Brown and C. V. Moore), p. 298. Grune \& Stratton, New York.

Charlton, R.W., Jacobs, P., Seftel, H. \& Bothwell, T.H. (1964) Effect of alcohol on iron absorption. British Medical Journal. 2, 1427.

Charlton, R.W., Jacobs, P., Torrance, J.D. \& BothWell, T.H. (1965) The role of the intestinal mucosa in iron absorption. Journal of Clinical Investigation, 44, 543.

Cheney, B. \& Finch, C.A. (1960) Effect of inosine on iron absorption in rats. Proceedings of the Society for Experimental Biology and Medicine, 103, 37.

Conrad, M.E., Berman, A. \& Crosby, W.H. (1962) Iron kinetics in Laennec's cirrhosis. Gastroenterology, 43, 385.

ConRaD, M.E. \& CrosbY, W.H. (1963) Intestinal mucosal mechanisms controlling iron absorption. Blood, 22, 406.

Crosby, W.H. (1963) The control if iron balance by the intestinal mucosa. Blood, 22, 441.

DAvis, A.E. \& BigGs, J.C. (1964) Iron absorption in haemochromatosis and cirrhosis of the liver. Australasian Annals of Medicine, 13, 201.

DAvis, P.S. \& Deller, D.J. (1966) Effect of xanthine-oxidase inhibitor (allopurinol) on radio iron absorption in man. Lancet, ii, 470.

Davis, P.S., Luke, C.G. \& Deller, D.J. (1966) Reduction of gastric iron-binding protein in haemochromatosis. Lancet, ii, 1431.

Deller, D.J., Edwards, R.G., Dart, G., Luke, C.G. \& DAVIS, P.S. (1969) Gastric iron binding substance (gastroferrin) in a family with haemochromatosis. Australasian Annals of Medicine, 18, 36.

FIELDING, J. (1965) Differential ferrioxamine test for measuring chelatable body iron. Journal of Clinical Pathology, 18, 88.

Finch, S.C. \& Finch, C.A. (1955) Idiopathic hemochromatosis: an iron storage disease. Medicine, 34, 381.

GolDBERG, L. \& SMITH, J.P. (1960) Iron overloading and hepatic vulnerability. American Journal of Pathology, 36, 125.

Green, S. \& MaZUR, A. (1957) Relation of uric acid metabolism to release of iron from hepatic ferritin. Journal of Biological Chemistry, 227, 653.
Gevirtz, N.R. (1967) Allopurinol and iron metabolism. Lancet, ii, 715 .

GrieVE, J.W. (1932) 'Haemochromatosis'. Medical Journal of Australia, ii, 758.

Haskins, D., Stevens, A.R., Finch, S.C. \& Finch, C.A. (1952) Iron metabolism. Iron stores in man as measured by phlebotomy. Journal of Clinical Investigation, 31, 543.

HARRIS, O.D. (1962) Haemochromatosis: a family study. Medical Journal of Australia, ii, 754.

Hennessy, W.B., Biggs, J.C. \& Garvan, J.M. (1967) Primary carcinoma of the liver in haemochromatosis. (Abstract). Australasian Annals of Medicine, 16, 263.

Hurst, P.E., Kakulas, B.A. \& Walters, M.N.I. (1961) Hepatoma developing in treated haemochromatosis: report of a case. Medical Journal of Australia, ii, 18.

IsaAcson, C., Seftel, H.C., Keeley, K.J. \& Bothwell, T.H. (1961) Siderosis in the Bantu: the relationship between iron overload and cirrhosis. Journal of Laboratory and Clinical Medicine, 58, 845.

JACOBS, A. \& Miles, P.M. (1969) Role of gastric secretion in iron absorption. Gut, 10, 226.

Kaldor, I. (1953) Studies of intermediary iron metabolism. III. The value of serum iron and iron-binding capacity measurements in clinical diagnosis. Australasian Annals of Medicine, 2, 206.

Kavin, H., Charlton, R.W., Jacobs, P., Green, R., TorRanCE, J.D. \& BothWell, T.H. (1967) Effect of the exocrine pancreatic secretions on iron absorption. Gut, 8, 556.

Knauer, C.M., Gamble, C.N. \& Monroe, L.S. (1965) The reversal of hemochromatotic cirrhosis of multiple phlebotomies: report of a case. Gastroenterology, 49, 667.

Kinney, T.D., Kaufman, N. \& Klavins, J.V. (1961) Xanthine oxidase activity and iron storage in the liver. Proceedings of the Society for Experimental Biology and Medicine, 108, 22.

Knoblauch, M. \& Hedinger, C. (1963) 'Die Hämochromatoseleber' Virchows Archiv für Pathologische Anatomie Und Physiologie. 337, 205.

KOEPKE, J.A. \& STEWART, W.B. (1964) Role of gastric secre tion in iron absorption. Proceedings of the Society for Experimental Biology and Medicine, 115, 927.

Lloyd, H.M., Powell, L.W. \& Thomas, M.J. (1964) Idiopathic haemochromatosis in menstruating women. Lancet, ii, 555.

MacDonald, R.A. (1961) Idiopathic hemochromatosis: a variant of portal cirrhosis and idiopathic hemosiderosis. Archives of Internal Medicine, 107, 606.

MacDonALD, R.A. (1963) Idiopathic hemochromatosis: genetic or acquired? Archives of Internal Medicine, 112, 184.

MACDONALD, R.A. (1966) 'Idiopathic hemochromatosis: acquired or inherited?' Controversy in Internal Medicine (Ed. by F. J. Ingelfinger, A. S. Relman and M. Finland), p. 276. Saunders, Philadelphia.

MacDonald, R.A., Endo, H. \& Pechet, G.S. (1968) Pathogenesis of experimental hemochromatosis: reticuloendothelial system disorder and excess iron. Gastroenterology, 54, 161.

MacDonald, R.A. \& Pechet, G.S. (1964) Liver and tissue iron: comparative studies and significance for hemochromatosis. Archives of Pathology, 77, 348.

MacDonald, R.A. \& Pechet, G.S. (1965) Tissue iron and hemochromatosis: comparative geographic studies in Ireland, Israel, Japan, South Africa and the United States. Archives of Internal Medicine, 116, 381.

MADDOX, K. (1933) The retina in haemochromatosis. British Journal of Ophthalmology, 17, 393.

MAdDOX, K. \& DurIE, E.B. (1934) Observations on haemochromatosis. Medical Journal of Australia, i, 463.

MANIS, J. (1969) Ferrous iron oxidation by intestinal mucosal homogenates and its possible relation to iron absorption. (Abstract). Journal of Clinical Investigation, 48, 55a. 
Manis, J. \& Schachter, D. (1962) Active transport of iron by intestine. Features of the two step mechanism. American Journal of Physiology. 203, 73.

Mazur, A. \& Carleton, A. (1965) Hepatic xanthine oxidase and ferritin iron in the developing rat. Blood, 26, 317.

Mazur, A., Green, S., Saha, A. \& Carleton, A. (1958) Mechanism of release of ferritin iron in vivo by xanthine oxidase. Journal of Clinical Investigation, 37, 1809.

MAZUR, A. \& SACKLER, M. (1967) Haemochromatosis and hepatic xanthine oxidase. Lancet, i, 254.

MoRGAN, E.H. (1961) Idiopathic haemochromatosis: a family study. Australasian Annals of Medicine, 10, 114.

McAllen, P.M., Coghill, N.F. \& Lubran, M. (1957) The treatment of haemochromatosis. Quarterly Journal of Medicine, 26, 251.

McGuinness, A.E. (1953) 'Haemochromatosis'. Medical Journal of Australia, i, 119.

McWhaE, D.M. (1922) 'Case of haemochromatosis'. Medical Journal of Australia, ii, 337.

Murray, M.J. \& Stein, N. (1968) The effects on iron absorption of gastrointestinal secretion from patients with irondeficiency anaemia and haemochromatosis. British Journal of Haematology, $15,87$.

Paterson, R.S. (1958) Haemochromatosis with diabetes mellitus. Medical Journal of Australia, i, 43.

Pechet, G.S., French, S.W., Levy, A.J. \& McDonald, R.A. (1965) Histologic and chemical tissue iron: significance for hemochromatosis. Archives of Pathology, 79, 452.

Perkins, K.W., McInnes, I.W.S., Blackburn, C.R.B. \& BEAL, R.W. (1965) Idiopathic hemochromatosis in children. Report of a family. American Journal of Medicine, 39, 118.

PiRarT, J. (1964) Douze ans de recul dans le traitement de l'hémochromatose par saignées répétées. Monde Médical, 40, 170.

Powell, L.W. (1965) Iron storage in relatives of patients with haemochromatosis and in relatives of patients with alcoholic cirrhosis and haemosiderosis. Quarterly Journal of Medicine, 34, 427.

Powell, L.W. (1966) Normal human iron storage and its relation to ethanol consumption. Australasian Annals of Medicine, 15. 110.

Powell, L.W. \& Emmerson, B.T. (1966) Haemosiderosis associated with xanthine oxidase inhibition. Lancet, i, 239.

Powell, L.W. \& Thomas, M.J. (1967) The use of diethylene triamine penta-acetic (D.T.P.A.) in the clinical assessment of total body iron stores. Journal of Clinical Pathology, 20, 896.

Powell, L.W. \& KeRR, J.F.R. (1970) Reversal of 'cirrhosis' in idiopathic haemochromatosis following long-term intensive venesection therapy. Australasian Annals of Medicine (Feb. issue).

Powell, L.W. \& Wilson, Elizabeth (1969). Proceedings of the Australian Society for Medical Research, 2, 284.

Powell, W.J. \& Klatskin, G. (1968) Duration of survival in patient with Laennec's cirrhosis. American Journal of Medicine, 44, 406.

Russell, E. (1925) Haemochromatosis. Medical Journal of Australia, i, 251

Sabesin, S.M. \& Thomas, L.B. (1964) Parenchymal siderosis in patients with pre-existing portal cirrhosis. A pathologic entity simulating idiopathic and transfusional hemochromatosis. Gastroenterology, 46, 477.

SAINT, E.G. (1963) Haemochromatosis. Medical Journal of Australia, i, 137.

SaINT, E.G. \& Hunt, B. (1955) Haemochromatosis with heart failure complicating congenital non-spherocytic haemolytic anaemia. Australasian Annals of Medicine, 4, 105.

Schade, S.G., Cohen, R.J. \& Conrad, M.E. (1968) Effect of hydrochloric acid on iron absorption. New England Journal of Medicine, 279, 672.

SCHEUER, P.J. (1968) Liver Biopsy Interpretation. Baillière, Tindall \& Cassell, London.
Seegmiller, J.E., Engelman, K., Klinenberg, J.R., Watts, R.W.E. \& Sjoerdsma, A. (1964) Xanthine oxidase and iron. New England Journal of Medicine, 270, 534.

Sewell, A. (1956) Case of haemochromatosis. Medical Journal of Australia, ii, 318.

SHELdon, J.H. (1935) Haemochromatosis. Oxford University Press, London.

Smith, P.M., Studley, F. \& Williams, R. (1969) Postulated gastric factor enhancing iron absorption in haemochromatosis. British Journal of Haematology, 16, 443.

Stokes, E.H. (1926) A case of haemochromatosis. Medical Journal of Australıa, xxvi.

Strohmeyer, G.W., Miller, S.A., Scarlata, R.W., MoOre, E.W., Greenberg, M.S. \& Chalmers, T.C. (1964) Effects of hypoxia on iron absorption and mobilization in the rat. American Journal of Physiology, 207, 55.

Stocks, A.E. \& Martin, F.I.R. (1968) Pituitary function in hemochromatosis. American Journal of Medicine, 45, 839.

Tuttle, S.G., Figueroa, W.G. \& Grossman, M.I. (1959) Development of hemochromatosis in a patient with Laennec's cirrhosis. American Journal of Medicine, 26, 655.

Tyrer, J.H., Powell, L.W. \& Burnett, W. (1966) Hémochromatose primitive constitutionnelle ou hémochromatose secondaire à une cirrhose alcoolique? Observation d'un cas compliqué d'hépatome malin et de thrombose de la veine porte. Presse Médicale, 74, 1135.

Udall, V. \& Bushby, S.R.M. (1966) Symposium on allopurinol. Gout with renal complications. Discussion: hepatic iron storage. Annals of the Rheumatic Diseases, 25, 704.

Walsh, R.J., Perkins, K.W. \& Blackburn, C.R.B. (1964) A genetic study of haemochromatosis. Abstracts, 10th Congress of International Society of Haematology. F.16.

Walsh, R.J., Perkins, K.W., Blackburn, C.R.B., SANDford R. \& Cantrill, S. (1963) The use of D.T.P.A. in the diagnosis and management of idiopathic haemochromatosis. Australasian Annals of Medicine, 12, 192.

WALSH, R.J. \& KING, W.E. (1950) Case of haemochromatosis. Medical Journal of Australia, ii, 179.

Walsh, J.R., Mass, R.E., Smith, F.W. \& Lange, V. (1965) Iron chelation with deferoxamine in hepatic disease. Gastroenterology, 49, 134.

Weintraub, L.R., Dawson, R.B. \& Rafal, S. (1968) Absorption of hemoglobin iron: the release of iron from heme by intestinal xanthine oxidase (Abstract). Journal of Clinical Investigation, 47, 101a.

Weintraub, L.R., Conrad, M.E. \& Crosby, W.H. (1966) The treatment of hemochromatosis by phlebotomy. Medical Clinics of North America, 50, 1579.

Westerfeld, W.W. \& Richert, D.A. (1952) The determination of xanthine oxidase in rat liver and intestine. Journal of Biological Chemistry, 199, 393.

Wigley, D.R. \& KING, W.E. (1956) Medical Journal of Australia, i, 898.

Williams, R., Pitcher, C.S., Parsonson, A. \& Williams, H.S. (1965) Iron absorption in the relatives of patients with idiopathic hemochromatosis. Lancet, i, 1243.

Williams, R., Williams, H.S., Scheuer, P.J., Pitcher, C.S., LoIseau, E. \& Sherlock, S. (1967) Iron absorption and siderosis in chronic liver disease. Quarterly Journal of Medicine, 36, 151

Williams, R., Smith, P.M., Spicer, E.J.F., Barry, M. \& SHERLOCK, S. (1969) Venesection therapy in idiopathic haemochromatosis. Quarterly Journal of Medicine, 38, 1.

WiLlis, R.A. (1941) 'Haemochromatosis with special reference to supervening carcinoma of the liver'. Medical Journal of Australia, ii, 666.

Wynter, C.V.A. \& Williams, R. (1968) Iron binding properties of gastric juice in idiopathic haemochromatosis. Lancet, ii, 534. 